\title{
Correlation between enzymatic estimation of infarct size and early mortality rate
}

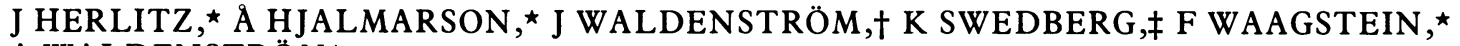 \\ A WALDENSTRÖM* \\ From the ${ }^{\star}$ Department of Medicine I, $†$ Department of Clinical Chemistry, Sahlgren’s Hospital; and $\ddagger$ Department of \\ Medicine, Östra Hospital, University of Göteborg, Göteborg, Sweden
}

SUMMARY In 585 patients with a first acute myocardial infarction the maximum activity of heat stable lactate dehydrogenase (EC 1.1.1.27) was correlated with mortality at three months. The patients participated in a double blind trial with metoprolol in acute myocardial infarction. In all patients not taking a beta blocker a highly significant correlation was found, but this was not evident in those who were. When patients with anterior or inferior infarctions treated with a placebo were analysed separately the correlation remained, as it did when the patients who were alive on the fourth day after the onset of pain were analysed separately. No correlation was observed between enzyme activity and three month mortality in these subgroups if only patients treated with metoprolol were included.

In a subsample of only 171 patients it was found that the maximum activity of creatine kinase (EC 2.7.3.2) and creatine kinase subunit B did not correlate with three month mortality regardless of treatment. Thus it is concluded that when a sufficiently large number of patients are investigated there is a highly significant correlation between the enzymatic estimation of infarct size and early mortality in acute myocardial infarction. This relation did not persist when patients treated with beta blockade were analysed.

Several studies have been performed to correlate serum enzyme activity with early mortality in acute myocardial infarction. In most reports the hospital mortality rate was used to evaluate early mortality. ${ }^{1-3}$ With a few exceptions, such as the study of Hofvendahl, ${ }^{4}$ a positive correlation has been found between these two variables. The maximum serum activity of aspartate aminotransferase (EC 2.6.1.1), creatine kinase, lactate dehydrogenase, and creatine kinase $M B$ have been measured. One of the disadvantages of many of these studies was the inclusion of patients with a previous myocardial infarction.

The purpose of this study was to correlate the maximum activity of heat stable lactate dehydrogenase, creatine kinase, and creatine kinase subunit $B$ in patients suffering a first definite myocardial infarction with mortality at three months.

\section{Patients and methods}

All the 585 patients fulfilled given criteria for a first definite myocardial infarction. They were admitted to

Accepted for publication 5 July 1983 the coronary care units of Sahlgren's Hospital and East Hospital in Gothenburg and of Skövde Hospital. Patients were included if their heart rate was $\geqslant 45$ beats/minute, their systolic blood pressure $\geqslant 100$ $\mathrm{mm} \mathrm{Hg}$, their PQ interval $<0.24 \mathrm{~s}$, and they had no sign of severe congestive heart failure (auscultatory pulmonary rales $\leqslant 10 \mathrm{~cm}$ ). The age range was $40-74$ years. All patients were participants in a double blind study with metoprolol (a selective beta blocker) in suspected acute myocardial infarction.

The criteria for definite myocardial infarction were two of the following: (a) chest pain of at least 15 minutes' duration; (b) increased aspartate aminotransferase activity above the upper reference value $(0.7 \mu \mathrm{kat} / \mathrm{l})$ in at least two consecutive samples with a lower value of alanine aminotransferase (EC 2.6.1.2) activity or one pathological value of aspartate aminotransferase activity in combination with heat stable lactate dehydrogenase activity above the discriminatory level $(4.3 \mu \mathrm{kat} / \mathrm{l})$ in at least one sample; (c) electrocardiographic changes with a new pathological $Q$ wave or appearance or disappearance of ST elevation or both combined with the development of $\mathrm{T}$ wave inversion in at least two of 12 standard leads or 
electrocardiographic changes in one lead in combination with one raised value for heat stable lactate dehydrogenase activity.

Heat stable lactate dehydrogenase activity was measured every 12 hours for 48 to 108 hours in all patients. For inclusion in the analysis at least three values had to be obtained with the highest value being above the discriminatory level. Creatine kinase and creatine kinase B activity was measured every six hours for 48 hours in a subgroup (171 patients). At least three values had to be recorded with the highest value in each patient being above the discriminatory level (creatine kinase $4.5 \mu \mathrm{kat} / \mathrm{l}$; creatine kinase B 0.15 $\mu \mathrm{kat} / \mathrm{l})$. The first sample of lactate dehydrogenase was taken $\leqslant 48$ hours after the onset of pain (in $90 \%$ of patients after $\leqslant 24$ hours). The first samples of creatine kinase and creatine kinase $B$ were taken $\leqslant 16$ hours after the onset of pain in all patients.

The maximum value of enzyme activity in each patient was used as a measurement of infarct size. The patients were divided into quartiles according to their maximum values and the mortality was calculated as a percentage within each quartile.

The heat labile isoenzymes of lactate dehydrogenase were inactivated according to the method described by Brydon and Smith. ${ }^{5}$ Lactate dehydrogenase, aspartate aminotransferase, and alanine aminotransferase activity was determined according to the method recommended by the Scandinavian Committee on Enzymes, ${ }^{6}$ creatine kinase activity according to a modified recommendation by the Scandinavian Committee on Enzymes, ${ }^{7}$ and creatine kinase $B$ activity according to an immune inhibition method described by Gerhardt and Waldenström. ${ }^{8}$ The unit katal is defined as the catalytic activity of an enzyme which catalyses at a reaction rate of $1 \mathrm{~mol} / \mathrm{s}$.

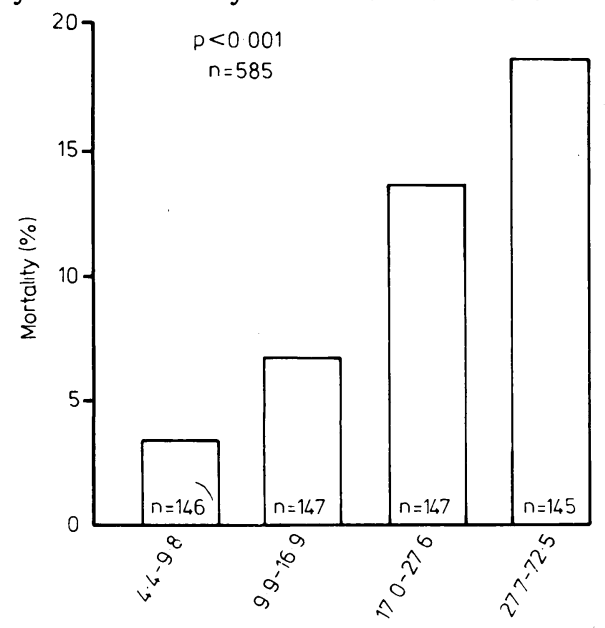

Maximum activity of heat stable lactate dehydrogenas $\in$ (

Fig. 1 Correlation between maximum activity of heat stable lactate dehydrogenase and three month mortality in all patients.
STATISTICAL METHODS

Pitman's test was used. Statistical significance was considered if a $p$ value $<0.05$ was observed in a two tail test.

\section{Results}

\section{HEAT STABLE LACTATE DEHYDROGENASE All patients}

A highly significant correlation between maximum activity of heat stable lactate dehydrogenase and three month mortality was found in the total series $(n=585$; p $<0.001$ ) (Fig. 1).

\section{Patients not taking beta blockers}

When all patients are included a highly significant correlation between maximum activity of heat stable lactate dehydrogenase and three month mortality was found ( $n=299 ; p<0.001)$. The mortality in each quartile was $4.0 \%, 4.1 \%, 14.5 \%$, and $27.0 \%$ (Fig. 2a). When patients with anterior myocardial infarction are analysed separately the correlation remained $(n=130$; $\mathrm{p}<0.001)$. The mortality in each quartile was then $6.3 \%, 5.9 \%, 9.4 \%$, and $37.5 \%$ (Fig. 2 b). In patients with inferior myocardial infarction there was also a significant correlation between enzyme activity and mortality $(\mathrm{n}=128, \mathrm{p}=0.003)$. Mortality in the four quartiles was $3 \cdot 1 \%, 0 \%, 18.8 \%$, and $21.9 \%$ (Fig. $2 \mathrm{c}$ ).

In order to evaluate the prognostic value of measuring maximum activity of heat stable lactate dehydrogenase all patients who died during the first three days in hospital were excluded from the analysis and the mortality in the remaining patients was studied. A correlation between infarct size and mortality persisted in this group, consisting of all patients as well as in patients with anterior and inferior myocardial infarction (Table 1).

Finally, when the patients in whom activity of creatine kinase and creatine kinase $B$ as well as of lactate dehydrogenase were measured were evaluated a weaker but still significant correlation between enzyme activity and mortality was found (Fig. 2d).

\section{Patients taking beta blockers}

When all patients taking beta blockers (metoprolol) were studied no correlation between enzyme activity and mortality was observed (Fig. 2a). In none of the subgroups previously described was a correlation found (Figs. 2b, 2c, and 2d; Table 2).

\section{CREATINE KINASE}

There was no significant relation between maximum creatine kinase activity and three month mortality when all patients were evaluated and when patients taking and not taking beta blockers were separately analysed (Fig. 3a). The mortality in each quartile in 


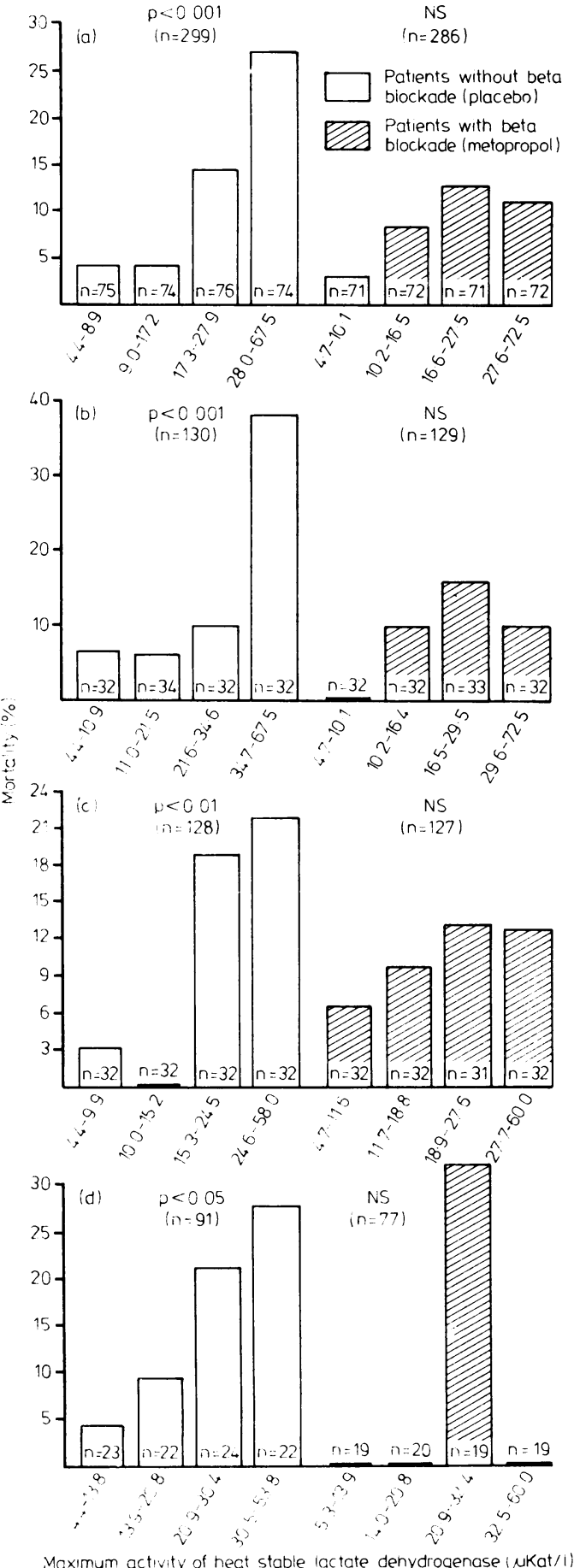

Fig. 2 Correlation between maximum activity of heat stable lactate dehydrogenase and three month mortality $(a)$ in all patients, $(b)$ in patients with anterior myocardial infarction, (c) in patients with inferior myocardial infarction, and $(d)$ in patients in whom creatine kinase and creatine kinase $B$ activity was measured. patients not taking beta blockers was $4.3 \%, 21 \cdot 7 \%$, $16 \cdot 7 \%$, and $21 \cdot 7 \%$ (Fig. 3a).

\section{CREATINE KINASE SUBUNIT B}

Maximum creatine kinase B activity was not significantly associated with early mortality (Fig. 3b). When patients not taking beta blockers were separately analysed the mortality in the lowest quartile was low (4.3\%; as in the case of creatine kinase) compared with $17.4 \%, 21.7 \%$, and $21.7 \%$ in the remaining three quartiles (Fig. 3b).

\section{Discussion}

Interest in the relation between infarct size and prognosis has increased since reports of the limitation of infarct size by different methods of treatment.910 Estimating infarct size is problematical and several methods are available. ${ }^{11}$ Enzymatic estimation is, like the other methods, prone to errors, ${ }^{12}$ although in several studies it has correlated well with necropsy findings. ${ }^{31314}$ Infarct size can be estimated by calculating the enzyme release and converting it to gram

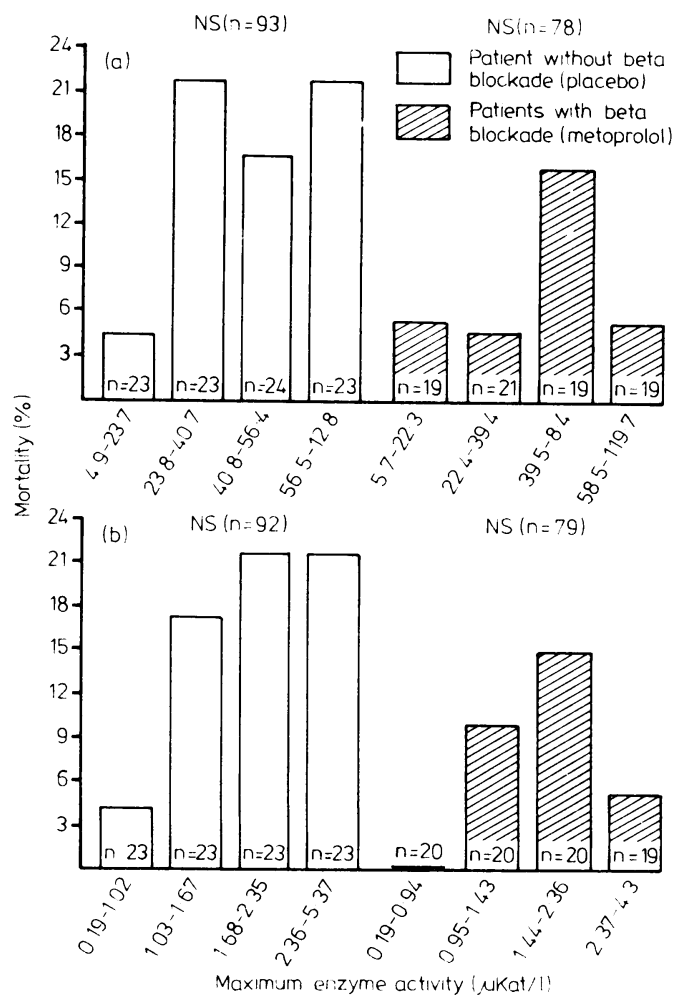

Fig. 3 Correlation between maximum activity of (a) creatine kinase and three month mortality and $(b)$ maximum activity of creatine kinase $B$ and three month mortality. 
Table 1 Three month mortality in relation to maximum activity of heat stable lactate dehydrogenase in patients alive during the first three days after the first enzyme sample and not taking beta blockers

\begin{tabular}{|c|c|c|c|c|c|}
\hline \multirow[b]{2}{*}{ Groups } & \multicolumn{4}{|l|}{ Quartiles } & \multirow[b]{2}{*}{ Probability } \\
\hline & lst & 2nd & $3 r d$ & $4 t h$ & \\
\hline $\begin{array}{l}\text { All patients with first infarction } \\
\text { Lactate dehydrogenase }(\mu \text { kat/l) } \\
\text { Mortality (\%) }\end{array}$ & $\begin{array}{l}4 \cdot 4-8 \cdot 9 \\
4 \cdot 2(n=72)\end{array}$ & $\begin{array}{l}9 \cdot 0-16 \cdot 9 \\
2 \cdot 7(n=75)\end{array}$ & $\begin{array}{l}17 \cdot 0-27 \cdot 6 \\
11 \cdot 1(n=72)\end{array}$ & $\begin{array}{l}27 \cdot 7-67 \cdot 8 \\
22 \cdot 2(n=72)\end{array}$ & $<0.001$ \\
\hline $\begin{array}{l}\text { Lactate dehydrogenase }(\mu \mathrm{kat} / \mathrm{l}) \\
\text { Mortality }(\%) \\
\text { Inferior and first infarction }\end{array}$ & $\begin{array}{l}4 \cdot 4-10 \cdot 6 \\
6 \cdot 2(n=32)\end{array}$ & $\begin{array}{l}10 \cdot 7-21 \cdot 3 \\
3 \cdot 1(n=32)\end{array}$ & $\begin{array}{l}21.4-32.5 \\
9.7(n=31)\end{array}$ & $\begin{array}{l}32 \cdot 6-67 \cdot 5 \\
29 \cdot 0(n=31)\end{array}$ & 0.005 \\
\hline $\begin{array}{l}\text { Lactate dehydrogenase }(\mu \mathrm{kat} / \mathrm{l}) \\
\text { Mortality }(\%)\end{array}$ & $\begin{array}{l}4.4-9.7 \\
3 \cdot 2(n=31)\end{array}$ & $\begin{array}{l}9 \cdot 8-15 \cdot 1 \\
0(n=32)\end{array}$ & $\begin{array}{l}15 \cdot 2-24 \cdot 4 \\
15 \cdot 6(n=32)\end{array}$ & $\begin{array}{l}24 \cdot 5-58 \\
19 \cdot 4(n=31)\end{array}$ & 0.008 \\
\hline
\end{tabular}

Table 2 Three month mortality in relation to maximum activity of heat stable lactate dehydrogenase in patients alive during the first three days after the first enzyme sample and taking beta blockers

\begin{tabular}{|c|c|c|c|c|c|}
\hline \multirow[b]{2}{*}{ Groups } & \multicolumn{4}{|l|}{ Quartiles } & \multirow[b]{2}{*}{ Probability } \\
\hline & lst & 2nd & $3 r d$ & $4 t h$ & \\
\hline \multicolumn{6}{|l|}{ All patients with first infarction } \\
\hline $\begin{array}{l}\text { Lactate dehydrogenase }(\mu \mathrm{kat} / \mathrm{l}) \\
\text { Mortality }(\%)\end{array}$ & $4 \cdot 7-10 \cdot 0$ & $10 \cdot 1-16 \cdot 4$ & $16 \cdot 5-27 \cdot 4$ & $27.5-72 \cdot 5$ & \\
\hline \multicolumn{6}{|l|}{ Anterior and first infarction } \\
\hline Lactate dehydrogenase $(\mu \mathrm{kat} / \mathrm{l})$ & $4 \cdot 7-10 \cdot 0$ & $10 \cdot 1-16 \cdot 2$ & $16 \cdot 3-29 \cdot 4$ & $29 \cdot 5-72 \cdot 5$ & \\
\hline \multicolumn{5}{|l|}{ Inferior and first infarction } & \\
\hline Lactate dehydrogenase $(\mu \mathrm{kat} / \mathrm{l})$ & $4 \cdot 7-11 \cdot 6$ & $11.7-18.9$ & $19 \cdot 0-27 \cdot 7$ & $27 \cdot 8-60$ & \\
\hline Mortality (\%) & $6 \cdot 3(n=32)$ & $3 \cdot 3(n=30)$ & $12.9(n=31)$ & $9 \cdot 7(n=31)$ & $>0.2$ \\
\hline
\end{tabular}

equivalents. ${ }^{15}$ These calculations give the same information as the maximum enzyme activity in most patients. ${ }^{16}$

The choice of enzyme as a marker of ischaemic damage has been discussed. ${ }^{17}$ Creatine kinase MB activity has been shown to be the most heart specific isoenzyme available. ${ }^{18}$ Nevertheless, the severity of the infarction, expressed as the incidence of heart failure or mortality rate, has in one small study been shown to correlate better with mitochondrial aspartate aminotransferase than with creatine kinase MB. ${ }^{19}$

In several previous reports the maximum enzyme activity was related to hospital mortality..$^{1-320}$ Most of these studies have included patients with a previous myocardial infarction, which makes them more difficult to interpret. Unspecific enzymes such as aspartate aminotransferase, creatine kinase, and lactate dehydrogenase have mainly been used. With a few exceptions, however, there has been a good correlation between maximum enzyme activity and hospital mortality.

In the present study, there was a good correlation between the maximum activity of heat stable lactate dehydrogenase and three month mortality in patients not taking beta blockers, which further supports the previous findings. In a smaller number of patients, however, maximum activities of creatine kinase and creatine kinase $B$ were not found to correlate significantly with early mortality. One reason may be that the intervals between the enzyme analyses were too long and that the peak value was therefore missed in some patients. Another explanation may be that the sample size was too small to detect a significant correlation. The conclusion cannot be drawn from these results that measurement of heat stable lactate dehydrogenase is to be preferred to that of creatine kinase or creatine kinase B. Nevertheless, the results do not indicate that creatine kinase $B$ measured every six hours-the most heart specific isoenzyme availableis a better determinant of prognosis than heat stable lactate dehydrogenase (measured every 12 hours). Heat stable lactate dehydrogenase has a relatively long half life and the measurement of the maximum activity of this enzyme was probably more accurate.

When three month mortality is studied in relation to indirect signs of infarct size, it is important to find out whether it is the extremely early mortality (in the first few days) that mainly influences the overall correlation or whether maximum enzyme activity could be used as a prognostic variable for patients who survive. In this study it was found that maximum activity of heat stable lactate dehydrogenase also correlated with three month mortality in patients who lived for more than three days.

The relation between heat stable lactate dehydrogenase activity and early mortality was observed in patients not taking beta blockers in the acute stage and during three month follow up, whereas treatment 
with beta blockade seemed to disturb the overall correlation. In the present study survival was increased overall in patients treated with metoprolol compared with those treated with placebo. ${ }^{21}$ The results indicate that beta blockade might reduce mortality to a higher degree in patients with larger infarcts. The overall death rate in patients with smaller infarcts was so low that no conclusions can be drawn from the present study on whether beta blockade influences mortality in this subset of patients.

This study was supported by grants from the Swedish Medical Research Council (projects No. B81-19X02529-12B and B82-19X-02529-13C), the Swedish National Association against Heart and Chest Diseases, the Göteborg Medical Society, and AB Hässle, a subsidiary of AB Astra, Sweden.

\section{References}

1 Sobel BE, Shell WE. Serum enzyme determinations in the diagnosis and assessment of myocardial infarction. Circulation 1972; 45: 471-82.

2 Thanavaro S, Krone RJ, Kleiger RE, et al. In-hospital prognosis of patients with first nontransmural and transmural infarctions. Circulation 1980; 61: 29-33.

3 Grande P, Fischer Hansen B, Christiansen C, Naestoft J. Acute myocardial infarct size estimated by serum CK-MB determinations: clinical accuracy and prognostic relevance utilizing a practical modification of the isoenzyme approach. Am Heart $\mathcal{F}$ 1981; 101: 582-6.

4 Hofvendahl S. Influence of treatment in coronary care unit on prognosis in acute myocardial infarction. Acta Med Scand 1971; suppl 519: 1-78.

5 Brydon WG, Smith AF. An appraisal of routine methods for the determination of the anodal isoenzymes of lactate dehydrogenase. Clin Chim Acta 1973; 43: 361-9.

6 Keiding R, Horder M, Gerhardt W, et al. The Committee on enzymes of the Scandinavian Society for Clinical Chemistry and Clinical Physiology (SCE). Recommended methods for the determination of four enzymes in blood. Scand $\mathcal{F}$ Clin Lab Invest 1974; 33: 291-306.

7 Hørder M, Magid E, Pitkänen E, et al. Recommended method for the determination of creatine kinase in blood modified by the inclusion of EDTA. Scand F Clin Lab Invest 1979; 39: 1-5.

8 Gerhardt W, Waldenström J. Creatine kinase B-subunit activity in serum after immunoinhibition of $M$-subunit. Clin Chem 1979; 25: 1274-80.
9 Maroko PR, Hillis LD, Muller JE, et al. Favorable effects of hyaluronidase on electrocardiographic evidence of necrosis in patients with acute myocardial infarction. $N$ Engl F Med 1977; 296: 898-903.

10 Maroko PR, Deboer LWV, Davis RF. Infarct size reduction: a critical review. Adv Cardiol 1980; 27: 12769.

11 Hillis LD, Askenazi J, Braunwald E, et al. Use of changes in the epicardial QRS complex to assess interventions which modify the extent of myocardial necrosis following coronary artery occlusion. Circulation 1976; 54: 591-8.

12 Roe CR. Validity of estimating myocardial infarct size from serial measurements of enzyme activity in the serum. Clin Chem 1977; 23: 1807-12.

13 Erhardt LR. Clinical and pathological observations in different types of acute myocardial infarction. Acta Med Scand 1974; suppl 560: 1-78.

14 Bleifeld W, Mathey D, Hanrath P, Buss H, Effert S. Infarct size estimated from serial serum creatine phosphokinase in relation to left ventricular hemodynamics. Circulation 1977; 55: 303-11.

15 Shell WE, Kjekshus JK, Sobel BE. Quantitative assessment of the extent of myocardial infarction in the conscious dog by means of analysis of serial changes in serum creatine phosphokinase activity. $\mathcal{F}$ Clin Invest 1971; 50: 2614-25.

16 Nordlander R, Nyquist O, Sylvén C. Estimation of infarct size by creatine kinase. A comparison between maximal value, planimetry and computer calculation. Cardiology 1981; 68: 201-4.

17 Sobel BE, Kjekshus JK, Roberts R. Enzymatic estimation of infarct size. In: Hearse DJ, de Leiris J, eds. Enzymes in cardiology, diagnosis and research. New York: John Wiley, 1979: 257-318.

18 Konttinen A, Somer H. Determination of serum creatine kinase isoenzymes in myocardial infarction. Am $\mathcal{f}$ Cardiol 1972; 29: 817-20.

19 Smith AF, Wong PC-P, Oliver MF. Release of mitochondrial enzymes in acute myocardial infarction. $\mathcal{f}$ Mol Med 1977; 2: 265-9.

20 Kibe O, Nilsson NJ. Observations on the diagnostic and prognostic value of some enzyme tests in myocardial infarction. Acta Med Scand 1967; 182: 597-610.

21 Hjalmarson A, Elmfeldt D, Herlitz J, et al. Effect on mortality of metoprolol in acute myocardial infarction. Lancet 1981; ii: 823-7.

Requests for reprints to Dr Johan Herlitz, Department of Medicine I, Sahlgren's Hospital, S-413 45 Göteborg, Sweden. 